\title{
Different responses of northern and southern high latitude ionospheric convection to IMF rotations: a case study based on SuperDARN observations
}

\author{
D. Ambrosino ${ }^{1}$, E. Amata ${ }^{1}$, M. F. Marcucci ${ }^{1}$, I. Coco ${ }^{1}$, W. Bristow ${ }^{2}$, and P. Dyson ${ }^{3}$ \\ ${ }^{1}$ Istituto di Fisica dello Spazio Interplanetario, IFSI - INAF, Roma, Italy \\ ${ }^{2}$ Geophysical Institute, UAF, USA \\ ${ }^{3}$ La Trobe Un., Victoria, Australia
}

Received: 2 September 2008 - Revised: 16 April 2009 - Accepted: 27 May 2009 - Published: 15 June 2009

\begin{abstract}
We use SuperDARN data to study high-latitude ionospheric convection over a three hour period (starting at 22:00 UT on 2 January 2003), during which the Interplanetary Magnetic Field (IMF) flipped between two states, one with $B_{y} \gg\left|B_{z}\right|$ and one with $B_{z}>0$, both with negative $B_{x}$. We find, as expected from previous works, that day side ionospheric convection is controlled by the IMF in both hemispheres. For strongly northward IMF, we observed signatures of two reverse cells, both in the Northern Hemisphere (NH) and in the Southern Hemisphere (SH), due to lobe reconnection. On one occasion, we also observed in the $\mathrm{NH}$ two viscous cells at the sides of the reverse cell pair. For duskward IMF, we observed in the NH a large dusk clockwise cell, accompanied by a smaller dawn cell, and the signature of a corresponding pattern in the SH. On two occasions, a three cell pattern, composed of a large clockwise cell and two viscous cells, was observed in the NH. As regards the timings of the $\mathrm{NH}$ and $\mathrm{SH}$ convection reconfigurations, we find that the convection reconfiguration from a positive $B_{z}$ dominated to a positive $B_{y}$ dominated pattern occurred almost simultaneously (i.e. within a few minutes) in the two hemispheres. On the contrary, the reconfiguration from a $B_{y}$ dominated to a northward IMF pattern started in the $\mathrm{NH} 8-13$ min earlier than in the SH. We suggest that part of such a delay can be due to the following mechanism: as IMF $B_{x}<0$, the northward-tailward magnetosheath magnetic field reconnects with the magnetospheric field first tailward of the northern cusp and later on tailward of the southern cusp, due to the IMF draping around the magnetopause.
\end{abstract}

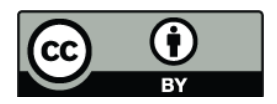

Correspondence to: D. Ambrosino (danila.ambrosino@ifsi-roma.inaf.it)
Keywords. Ionosphere (Auroral ionosphere; Ionospheremagnetosphere interactions) - Space plasma physics (Magnetic reconnection)

\section{Introduction}

Ionospheric convection patterns resulting from reconnection at the Earth's magnetopause have been the object of a vast literature which has studied their dependence on Interplanetary Magnetic Field (IMF) orientation by means of lowaltitude spacecraft (Heppner and Maynard, 1987; Weimer, 1995), ground magnetometers (Kamide et al., 1994; Papitashvili et al., 1994) and, more recently, SuperDARN convection measurements (Ruohoniemi and Greenwald, 1996, 2005; Chisham et al., 2007). On the other hand, a detailed understanding of high latitude ionospheric convection has been achieved in the course of years starting, for instance, from the seminal work of Cowley and Lockwood (1992).

For a southward IMF, reconnection takes place at the low latitude day side magnetopause, so that newly opened flux is transferred to the night side and two convection cells are set up in both hemispheres with anti-sunward flow in the polar caps. The relative dimensions and orientations of the two cells are known to depend upon the relative importance of the IMF $B_{z}$ and $B_{y}$ components: for $B_{y}>\left|B_{z}\right|$ dusk and dawn cells dominate in the Northern Hemisphere (NH) and in the Southern Hemisphere (SH) respectively; the opposite situation occurs when $B_{y}<B_{z}<0$. In the extreme condition of a purely $B_{y}>0$ field, Reiff and Burch (1985) forecast the formation of a single large clockwise cell in the $\mathrm{NH}$ and a counter-clockwise cell in the SH. Moreover, for all IMF conditions they forecast the presence of two lower latitude

Published by Copernicus Publications on behalf of the European Geosciences Union. 
viscous cells, at dusk and dawn with respect to the main convection pattern over the central polar cap.

For strongly northward IMF, reconnection is thought to occur tailward of the cusps (lobe reconnection), thus generating two reverse cells with sunward flow over the polar cap. There has been disagreement in the past over the detailed patterns of ionospheric convection resulting from strongly northward IMF. Burke et al. (1979) and Reiff and Burch (1985) suggested the existence of four convection cells: two reverse cells at high latitudes driven by lobe reconnection, and two normal cells at lower latitudes driven by viscous processes at the magnetopause. On the contrary, Heppner and Maynard (1987) suggested that only two highly-distorted cells would develop, while Rich and Hairstone (1994) performed a statistical study and found that four-cell convection occurred very rarely. Conversely, Ruohoniemi and Greenwald (1996) using SuperDARN data showed that, on a statistical basis, a fourcell structure existed for strong northward IMF. Their statistical convection patterns clearly showed two reverse convection cells poleward of $80^{\circ}$ MLAT near the noon meridian, which were almost completely contained within the day side ionosphere. In this regard, Milan et al. (2000) first used SuperDARN observations to infer the presence of a clockwise lobe cell for northward IMF with $B_{y} \simeq 0$, while Huang et al. (2000a) showed that the four cell convection configuration develops and is stable during steady northward IMF conditions.

Finally, the magnetic dipole tilt could favour lobe reconnection in the $\mathrm{NH}$ during the local summer and in the $\mathrm{SH}$ during the local summer. However, a large $B_{x}$ is believed to alter this seasonal effect (Cowley, 1983; Crooker and Rich, 1993; Lockwood and Moen, 1999).

In the last few years, interest has been growing in comparing how northern and southern ionospheric convection respond to reconnection at the magnetopause. Amata et al. (2008) recently published a preliminary study of the day side ionospheric convection as a function of IMF orientation over a three hour interval when the IMF flipped between two states, positive $B_{y}$ dominated and positive $B_{z}$, both with $B_{x}<0$. In this paper, we study in more detail such a period, confirm quantitatively the suggestions made by Amata et al. (2008) and discuss them more thoroughly. Section 2 presents an overview of interplanetary and magnetosheath conditions during the period under study based on IMF and plasma data from the Advanced Composition Explorer (ACE) and magnetosheath magnetic field from Cluster 2; Sect. 3 briefly recalls the significance of SuperDARN data to the study of high latitude ionospheric convection; the response of day side convection to four IMF rotations is described in Sects. 4 and 5, in the $\mathrm{NH}$ and in the SH, respectively; Sect. 6 concentrates on measurements of the line of sight velocity by the Kodiak radar in the NH and by the TIGER radar in the SH between 11:00 and 12:00 MLT, showing that, when the IMF turns from dominant $B_{y}$ to positive $B_{z}$, the $\mathrm{NH}$ and $\mathrm{SH}$ display different time responses; Sect. 7 presents a discussion of the observations, while Sect. 8 gives a short summary of our findings.

\section{Event overview}

Figure 1 displays, from top to bottom, solar wind dynamic pressure, $P_{\mathrm{dyn}}$, IMF $B_{x}, B_{y}, B_{z}$, in GSM, and clock angle (all as dashed lines) measured close to the $\mathrm{L} 1$ libration point, at $(242.1 ;-18.6 ; 15.5) R_{E}$ GSM, by ACE for 160 min starting at 21:50 UT on 2 January 2003. The four lower panels also display $B_{x}, B_{y}, B_{z}$, in GSM, and the clock angle (as solid lines) as observed by Cluster spacecraft 2 (Balogh et al., 1997) in the magnetosheath during an outbound orbit between $(-1.1 ; 0.9 ; 7.7)$ and $(0.9 ; 4.4 ; 9.5) R_{E}$ GSM very close to the magnetopause, tailward and slightly duskward of the nominal location of the northern cusp. We shifted ACE data by $67 \mathrm{~min}$ to match the Cluster $2 B_{z}$ component after 23:25 UT; however, we notice that this shift does not yield a perfect alignment of the $B_{y}$ components and of the clock angles. In fact, starting from 00:08 UT on 3 January 2003 the ACE $B_{y}$ changed from positive to negative and then oscillated around $0 \mathrm{nT}$, while the Cluster $2 B_{y}$ dropped to $0 \mathrm{nT}$ at 00:15 UT and then remained negative approching $0 \mathrm{nT}$ from time to time. This discrepancy probably means that the IMF structures underwent some evolution between L1 and the Earth's orbit. Throughout the event, at ACE $B_{x}<0$, while $B_{y}$ was clearly positive, apart from short intervals when it approached $0 \mathrm{nT}$.

We notice that four major IMF rotations occurred, as evidenced by vertical solid lines. Line A, drawn at 22:07 UT, marks a rotation where the ACE clock angle, defined as $\theta=\arctan \left(B_{y} / B_{z}\right)$, changed from $\theta \simeq 45^{\circ}$ to $\theta \simeq 90^{\circ}$. At line B (22:45 UT) the ACE clock angle fell from $\theta \simeq 90^{\circ}$ to $\theta \simeq 0^{\circ}$ and then varied between $\theta \simeq 0^{\circ}$ and $\theta \simeq 45^{\circ}$ until the next clear rotation. At line $\mathrm{C}$ (23:18 UT) $\theta$ jumped to $\simeq 90^{\circ}$. Line D is drawn at 23:49 UT, when Cluster $2 B_{x}$ turned negative, just when $B_{z}$ rose from slightly negative values to zero; after that, a slow rotation occurred over about $15 \mathrm{~min}$ during which $\theta$ dropped from $\simeq 90^{\circ}$ to $\simeq 0^{\circ}$. The timing of the $\mathrm{D}$ rotation is reliable, because it is based on Cluster 2 IMF data in the magnetosheath close to the magnetopause and to the northern cusp. Conversely, the times when the other three IMF rotations reached the magnetopause cannot be exactly determined as, at those times, Cluster 2 was in the magnetosphere. Finally we remark that during the whole period the solar wind dynamic pressure generally increased from $\simeq 5.52$ to $\simeq 11.1 \mathrm{nPa}$, which was due mainly to the increase of the solar wind number density, while the $\mathrm{x}$ component of the solar wind velocity was rather constant, $V_{x} \simeq-390 \mathrm{~km} / \mathrm{s}$. The main increase of dynamic pressure occurred close to rotation A, from 5.1 to $8.12 \mathrm{nPa}$ and a smaller increase occurred at rotation $\mathrm{C}$, from 8.12 to $9.05 \mathrm{nPa}$; on the other hand, at rotation $\mathrm{B}$ the pressure decreased by $1.16 \mathrm{nPa}$ to start increasing 


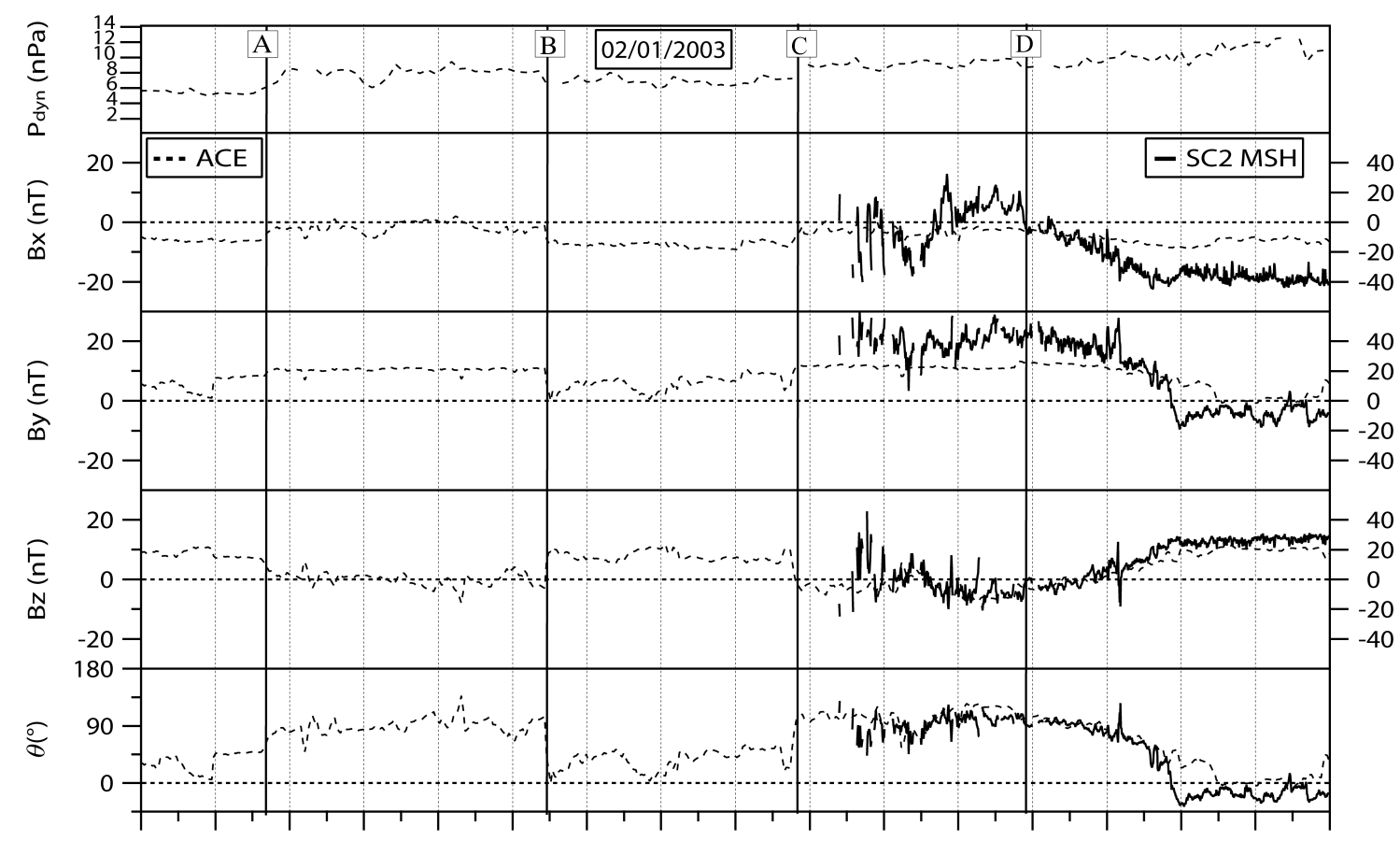

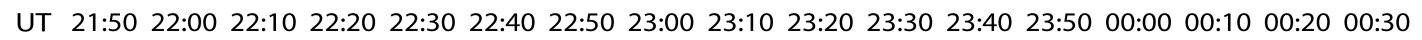

Fig. 1. From top to bottom: ACE dynamic pressure (computed by supposing that alpha particles contribute with a density equal to $4 \%$ of the proton density), GSM $B_{x}, B_{y}$ and $B_{z}$ and clock angle, defined as $\theta=\arctan \left(B_{y} / B_{z}\right)$, from ACE (dashed lines) and Cluster 2 in the magnetosheath (solid lines). The vertical solid lines mark the A, B and C IMF rotations and the start of the D rotation (see text for details). ACE data have been time shifted by $67 \mathrm{~min}$. Dotted zero lines are also shown in the four lower panels.

again after a few minutes, while during the long $\mathrm{D}$ rotation it increased slightly from 8.82 to $9.74 \mathrm{nPa}$.

\section{SuperDARN data and convection maps}

The Super Dual Auroral Radar Network (SuperDARN) is a successful network of NH and SH HF radars to study the ionospheric convection in the auroral and polar regions (Greenwald et al., 1995; Chisham et al., 2007). Each radar, in the common mode of operation, performs measurements of the line of sight velocity $\left(V_{\mathrm{LOS}}\right)$ of the ionospheric plasma, between 90 and $400 \mathrm{~km}$ altitude, with a time resolution of 1 or 2 min, along 16 azimuthal beams separated by $\simeq 3^{\circ}$, each consisting of 75 range gates between 180 and $3500 \mathrm{~km}$ from the radar site. The examination of the time evolution of $V_{\mathrm{LOS}}$ measured by each radar as a function of Magnetic Local Time (MLT) and magnetic latitude (MLAT) allows to pinpoint the response of high latitude convection to changes induced by interplanetary disturbances, e.g. IMF rotations. In addition, over many years a technique, called map potential, has been developed and extensively used to reconstruct $\mathrm{NH}$ and SH convection maps from SuperDARN data according to the method described by Ruohoniemi and Baker (1998) and Shepherd and Ruohoniemi (2000).
The performance of the map potential software critically depends on the SuperDARN data coverage. SuperDARN radars do not cover all MLT's and MLAT's, so that, even when valid echoes are available from a large portion of the radar fields of view (FOV), the map potential software makes use of additional data points determined by a statistical model of convection (Ruohoniemi and Baker, 1998; Ruohoniemi and Greenwald, 1996, 2005) to properly close the expansion in spherical harmonics. When the radar data coverage is good, the reconstructed maps over the regions where radar data are present are unequivocally determined by the actual measurements. On the other hand, as the data coverage reduces, the role played by the model increases and great care must be put in the interpretation of the reconstructed patterns.

During the period under study, data from 9 NH SuperDARN radars were available so that the NH coverage was good between $\simeq 65^{\circ}$ and $\simeq 90^{\circ}$ MLAT and from 09:00 MLT through 24:00 or even 03:00 MLT. In particular, on the day side data were provided by the King Salmon, Kodiak, Prince George, Saskatoon and Kapuskasing radars, while the Goose Bay, Stokkseyri, Thykkvibaer and Hankasalmi radars contributed to the convection maps on the evening side and on the night side. Starting from the available data we reconstructed $\mathrm{NH}$ convection maps throughout the event. In order 


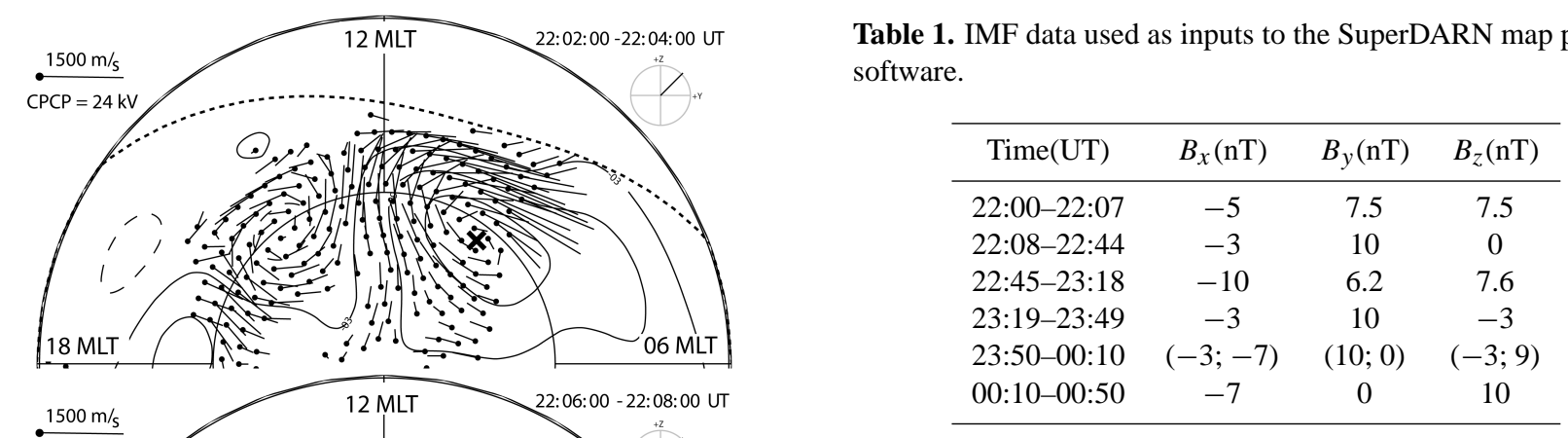

ing IMF data are shown in Table 1, which consists of 5 periods of constant IMF and 1 period (23:50-00:10 UT) during which each IMF component varied linearly with time. We recall that the map potential software chooses the convection statistical model on the basis of $B_{y}, B_{z}$ and B (i.e. $B_{x}$ is used for the calculation of $\mathrm{B}$ only). As a final test on the validity of the $\mathrm{NH}$ maps, we reconstructed them under two different conditions: a) using the IMF values listed in Table 1 ; b) using the Table $1 B_{x}$ and $B_{y}$ values, but forcing $B_{z}=-3 \mathrm{nT}$. As expected, apart from minor details, the maps did not change significantly, thanks to the large number of experimental data available throughout the period. In the next section, for each of the IMF rotations identified in Fig. 1 we will describe in detail the day side part of several maps calculated by using the IMF values of Table 1 .

For the SH the coverage is much less: 5-9 MLT hours on the day side, mainly at dawn near noon MLT, between $\simeq-75^{\circ}$ and $\simeq-85^{\circ}$ MLAT, provided by the TIGER radar; 5-9 MLT hours on the night side, around midnight MLT, between $\simeq-75^{\circ}$ and $\simeq-85^{\circ}$ MLAT, provided by the Halley, Sanae, Syowa East and Syowa South radars. This means that, although enough data are available to reconstruct the general features of convection patterns thanks to the presence of data both on the day side and on the night side, on the day side such reconstructions must be regarded as qualitative. Therefore, in Sect. 5 we study the response of SH ionospheric convection to the IMF rotations mainly by looking at FOV plots of measured $V_{\text {LOS }}$ to avoid any artefact from the statistical model used by the map potential software.

\section{Effects of the IMF rotations on NH convection}

\subsection{The first rotation to dominant $B_{y}$}

Figure 2 displays four $\mathrm{NH}$ day side convection maps for the 22:02-22:04, 22:06-22:08, 22:10-22:12, and 22:1822:20 UT intervals. As we noted in the description of Fig. 1, apart from a 4 min period after 21:55 UT, the IMF already had a substantial $B_{y}$ component prior to the 22:07 UT rotation. The main feature of the corresponding $\mathrm{NH}$ pattern (top panel) is a pair of reverse cells, centred at 15:00 MLT and $80^{\circ}$ MLAT and at 09:30 MLT and $81^{\circ}$ MLAT. Between 
them a clear sunward flow heads from the polar cap along noon MLT and bends mainly towards dawn at $80^{\circ}$ MLAT. The map also displays the signature of a small clockwise cell in the evening side, while no data are available in the 06:0009:00 MLT region below $73^{\circ}$ MLAT.

In the next 4 min the $\mathrm{NH}$ map does not change significantly, as illustrated by the 22:06-22:08 UT panel, apart from the appearance of a sunward flow at 09 MLT below $76^{\circ}$ MLAT (resembling a portion of a counter-clockwise cell) and the strengthening of a clockwise partial dusk cell centred at 17:30 MLT and $76^{\circ}$ MLAT (which are both fully reconstructed in the following convection maps). We interpret this pattern as composed of 2 reverse cells and 2 viscous cells (see e.g. Reiff and Burch, 1985).

The NH convection patterns show the start of a reconfiguration during the next $2 \mathrm{~min}$ (not shown), just at the time of the nominal IMF rotation (cf. Table 1). The reconfiguration then proceeded further as illustrated by the 22:10-22:12 UT map: the dusk side reverse cell has disappeared, but a clear sunward flow is still present from the polar cap around noon MLT. Moreover, we also notice the persistence of a sunward flow at 09:00 MLT below $76^{\circ}$ MLAT (resembling a portion of a counter-clockwise cell) and the strengthening of the dusk clockwise cell at 17:00 MLT and $77^{\circ}$ MLAT, which appears to be the evolution of the dusk evening cell partially reconstructed in the 22:02 and 22:06 UT maps.

In the next two min (not shown) the reconfiguration is complete, as the sunward flow from the polar cap disappears and a large clockwise cell centred at $82^{\circ}$ MLAT and at noon MLT is established. This new convection pattern remains stable for about $20 \mathrm{~min}$, as illustrated in the bottom panel at 22:18-22:20 UT. We see that the map now displays a clear three cell pattern, as the central noon MLT cell is accompanied by a dusk clockwise cell (focus at 17:00 MLT and 79 MLAT), which can be regarded as a "left over" of the dusk evening cell observed in the previous maps, and by a clear counter-clockwise cell at dawn (focus at 09:30 MLT and $77^{\circ}$ MLAT).

In summary, in the $\mathrm{NH}$ the reconfiguration from $B_{z}>0$ to dominant $B_{y}>0$ starts at 22:08 UT and ends at 22:14 UT.

\subsection{The first IMF northward turning}

Figure 3 displays five $\mathrm{NH}$ day side convection maps for the 22:36-22:38, 22:46-22:48, 22:54-22:56, 23:00-23:02 and 23:04-23:06 UT intervals. The top panel shows that, prior to the IMF rotation, the $\mathrm{NH}$ convection pattern exhibited a large dusk clockwise cell centred at 13:00 MLT and 83 $3^{\circ}$ MLAT and a smaller counter-clockwise dawn cell separated by a clear anti-sunward and dawnward flow extending from $77^{\circ}$ MLAT and 13:00 MLT to $82^{\circ}$ MLAT and 09:00 MLT. Such a pattern clearly results from the evolution of that shown in the bottom panel of Fig. 2.

The next three 2-min maps, which we do not show, present evidence of a slow evolution of the $\mathrm{NH}$ convection pattern.

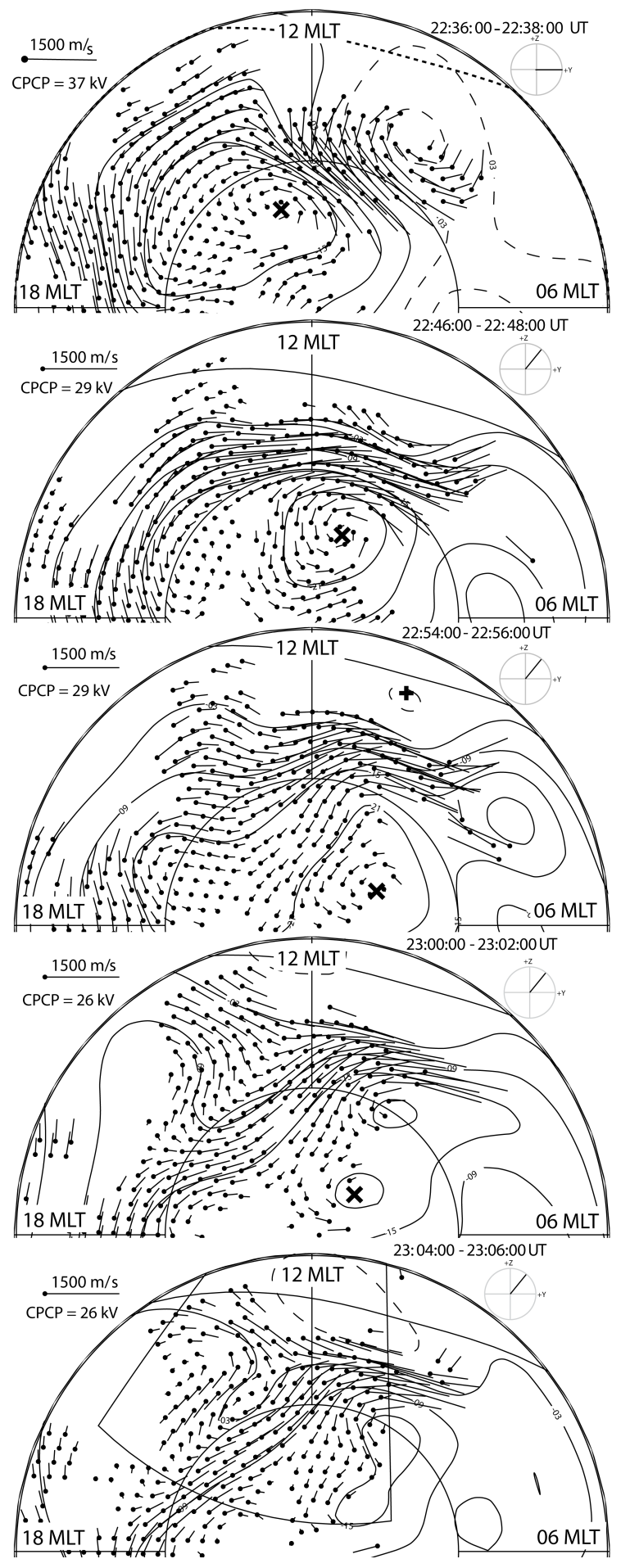

Fig. 3. SuperDARN NH dayside convection maps for rotation B of the IMF. Same format as in Fig. 2.

Eventually, the 22:46-22:48 UT map shows: a) a clockwise cell centred at noon MLT and $83^{\circ}$ MLAT (producing a sunward flow at $82^{\circ}-84^{\circ}$ MLAT and 12:00-13:00 MLT), b) a 

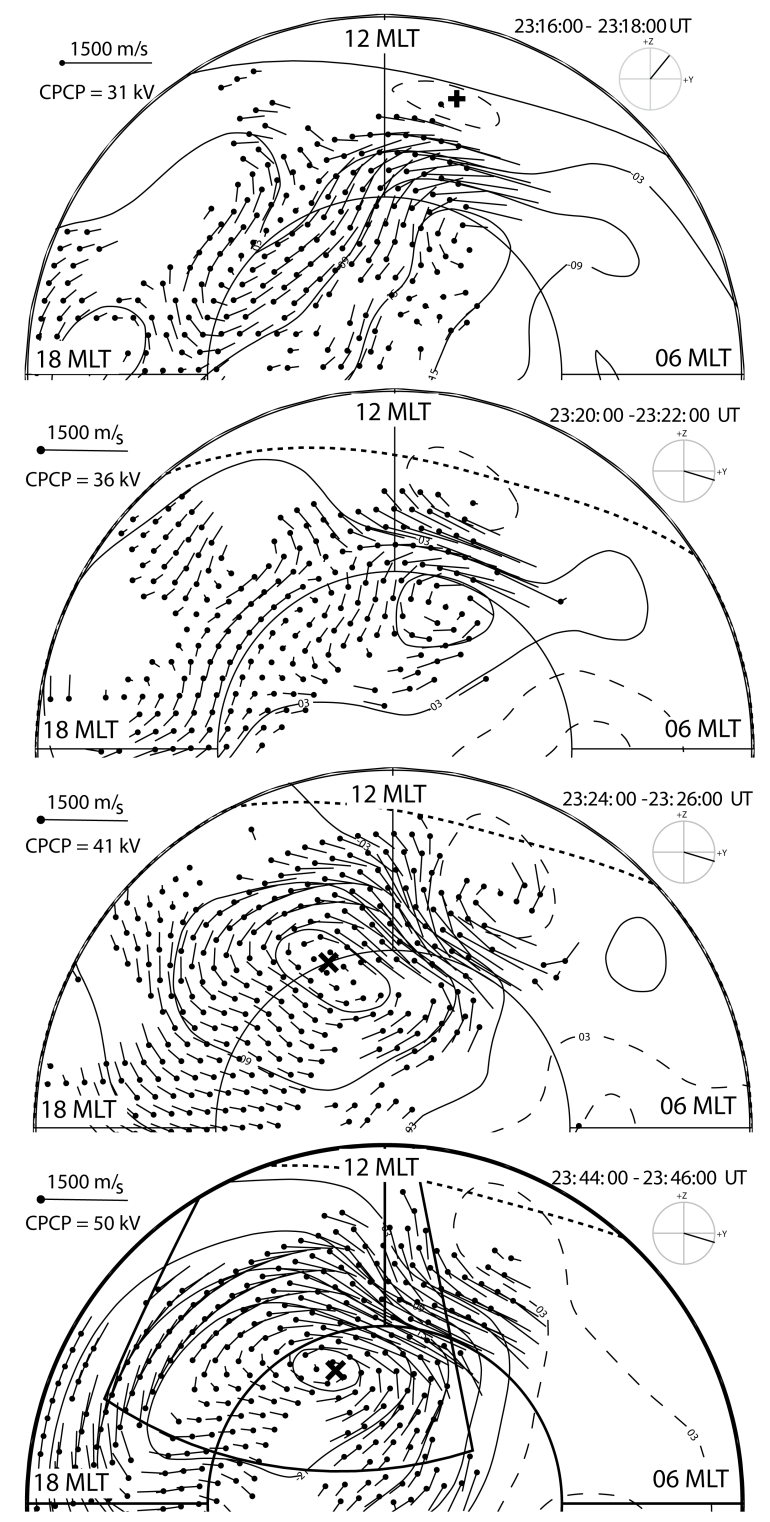

Fig. 4. SuperDARN NH dayside convection maps for rotation C of the IMF. Same format as in Fig. 2.

small clockwise cell at dusk with focus at $81^{\circ}$ MLAT and 16:00 MLT, c) a portion of the dawn cell (which seems to have moved sunward), d) a mainly dawnward flow extending from 15:00 to 09:00 MLT at $77^{\circ}-80^{\circ}$ MLAT.

In the next $8 \mathrm{~min}$ the $\mathrm{NH}$ pattern further evolves and the noon MLT cell shifts toward dawn (Huang et al., 2000a). At 22:54-22:56 UT (third panel from the top) the focus of this cell is located at $85^{\circ}$ MLAT and 08:30 MLT, while the clockwise cell centred at $81^{\circ}$ MLAT and 16:00 MLT has faded. At the same time the dawn counter-clockwise cell is not visible any more.
In the next 4 min (not shown) the sunward flow around noon MLT between $80^{\circ}$ and $90^{\circ}$ MLAT widens in MLT and the signature of a counter-clockwise cell appears centred at 14 MLT and $78^{\circ}$ MLAT, as illustrated in the fourth panel from the top (23:00-23:02 UT). Moreover, the dusk quadrant displays the signature of a clockwise vortex stretching from 13:00-18:00 MLT, probably due to a large viscous cell. The final result of this evolution is shown in the bottom panel (23:04-23:06 UT). The main features of this NH map are: a) a sunward flow extending from high latitude in the polar cap and crossing 82 $2^{\circ}$ MLAT from 09:00 to 13:00 MLT, b) the mainly dawnward flow across noon MLT at $77^{\circ}$ MLAT, c) the new partial counter-clockwise cell centred at 13:30 MLT and $78^{\circ}$ MLAT; d) the signature of a dusk viscous cell. Although we do not see two clear reverse cells, there is no doubt that this pattern is due to reconnection tailward of the $\mathrm{NH}$ cusp.

In summary, in the $\mathrm{NH}$ the reconfiguration from dominant $B_{y}>0$ to $B_{z}>0$ starts around 22:45 UT and ends at 23:02 UT.

\subsection{The second rotation to dominant $B_{y}$}

Figure 4 displays four $\mathrm{NH}$ dayside convection maps for the $23: 16-23: 18,23: 20-23: 22,23: 24-23: 26$, and $23: 44-$ 23:46 UT intervals. The top panel map shows the last convection map before the nominal 23:18 UT IMF rotation and is similar to the three preceding ones (which we do not show). As it can be seen from Fig. 1, between 22:26 and 23:18 UT the IMF already slowly rotated and a substantial $B_{y}$ component had developed. The main feature of the top panel NH pattern is the sunward flow which heads from the polar cap (slightly from the dusk side) along noon MLT and bends towards dawn at $80^{\circ}$ MLAT, thus suggesting the existence of a clockwise lobe cell, not fully resolved due to the lack of data in the first half of the dawn quadrant. The signature of a partial clockwise cell is seen in the dusk quadrant centred at $\simeq 77^{\circ}$ MLAT and 14:30 MLT. Moreover, a clockwise cell is seen centred at 17:30 MLT and $\simeq 73^{\circ}$ MLAT. Such a pattern clearly results from the evolution of the ones shown in the bottom panel of Fig. 3.

In the next 2 min we see evidence that the convection pattern is changing. This is the time of the nominal IMF rotation (cf. Table 1) and a transient clockwise cell appears centred at $82^{\circ}$ MLAT and 11:00 MLT which is limited at lower latitudes by the pre-existing dawnward flow around noon MLT and at higher latitudes by a duskward and slightly tailward flow. As part of the pattern evolution, the partial counter-clockwise cell centred at $\simeq 79^{\circ}$ MLAT and 14:00 MLT has disappeared, while the clockwise cell formerly centred at 17:30 MLT and $\simeq 73^{\circ}$ MLAT has faded and moved slightly sunward.

The reconfiguration is complete in the next map (not shown) and can be seen in the third panel from the top (23:24-23:26 UT): the sunward flow around noon MLT has disappeared and a large clockwise dusk cell extends partially to the dawn quadrant; moreover, a smaller dawn cell appears 
separated from the dusk cell by a dusk-dawn and tailward flow across noon MLT at $75^{\circ}-80^{\circ}$ MLAT. This situation remains essentially unchanged in the next $25 \mathrm{~min}$, as illustrated by the bottom panel (23:44-23:46 UT).

In summary, this reconfiguration from $B_{z}>0$ to dominant $B_{y}>0$ starts at 23:18 UT and ends at 23:24 UT.

\subsection{The second IMF northward rotation}

Figure 5 displays five $\mathrm{NH}$ day side convection maps for the 23:58-00:00, 00:06-00:08, 00:16-00:18 UT, 00:18-00:20 and 00:26-00:28 UT intervals. A slow rotation of the IMF starts at 23:49 UT (see Fig. 1) and makes the Cluster 2 clock angle drop from $90^{\circ}$ to below $0^{\circ}$ in $20 \mathrm{~min}$. The effects of this rotation in the convection maps show up gradually. In fact, the NH convection pattern for 23:58-00:00 UT (top panel) shows a large dusk clockwise cell extending to the dawn quadrant, which is still clearly due to $B_{y}$ dominated reconnection and looks like the evolution of the pattern in the bottom panel of Fig. 4.

In the next six minutes, similarly to what was observed for the first northward IMF rotation, an evolution of the $\mathrm{NH}$ pattern is observed until a sunward flow develops at $80^{\circ}-85^{\circ}$ MLAT and 11:00-13:00 MLT, which appears to deflect towards the Sun the dawn-dusk flow at lower latitudes. This can be seen in the 00:06-00:08 UT panel, i.e. when the clock angle was $\simeq 45^{\circ}$ (see Fig. 1) and the Cluster $2 B_{z} \simeq 5 \mathrm{nT}$.

The following four 2-min $\mathrm{NH}$ maps all display a duskdawn flow at $75^{\circ}-78^{\circ}$ MLAT and 11:00-13:00 MLT and a sunward flow from the polar cap down to $\simeq 80^{\circ}$ MLAT around noon MLT, while the IMF has completed its northward rotation at 00:10 UT. At 00:16-00:18 UT, a counterclockwise cell starts developing at dusk, centred at $76^{\circ}$ MLAT and 14:30MLT, while the dawn-dusk flow around noon MLT appears reduced in extension and intensity. At 00:18-00:20 UT the next map shows that the dusk side counter-clockwise cell centred at 14:30 MLT has fully developed.

In the following minutes the $\mathrm{NH}$ maps keep a constant topology, but for the emergence of a large clockwise cell, centred at 17:00 MLT and 73 MLAT, which can be probably attributed to a viscous cell, as illustrated by the 00:2600:28 UT map displayed in the bottom panel. The main feature of such map is the dusk counter-clockwise cell roughly at the centre of the dusk quadrant, which can be interpreted as the dusk cell of the expected two reverse cell system, while the dawn cell cannot be resolved due to the lack of data coverage. We also notice that the dawnward flow at 10:00-12:00 MLT continues to fade, until, after 00:30 UT (not shown), it ceases completely.

In summary, the last $\mathrm{NH}$ reconfiguration from $B_{y}>0$ dominated to $B_{z}>0$ dominated starts at 00:04 UT and ends at 00:20 UT.
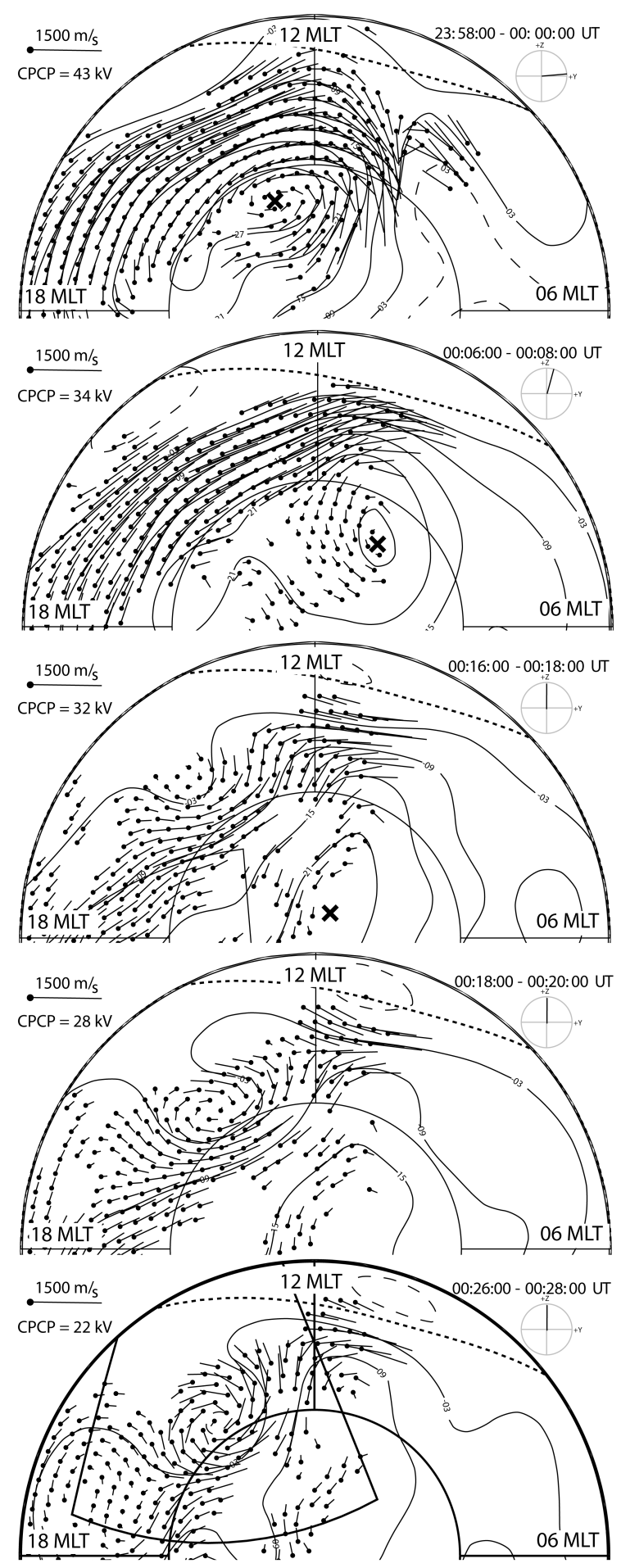

Fig. 5. SuperDARN NH day sideconvection maps for rotation D of the IMF. Same format as in Fig. 2. 


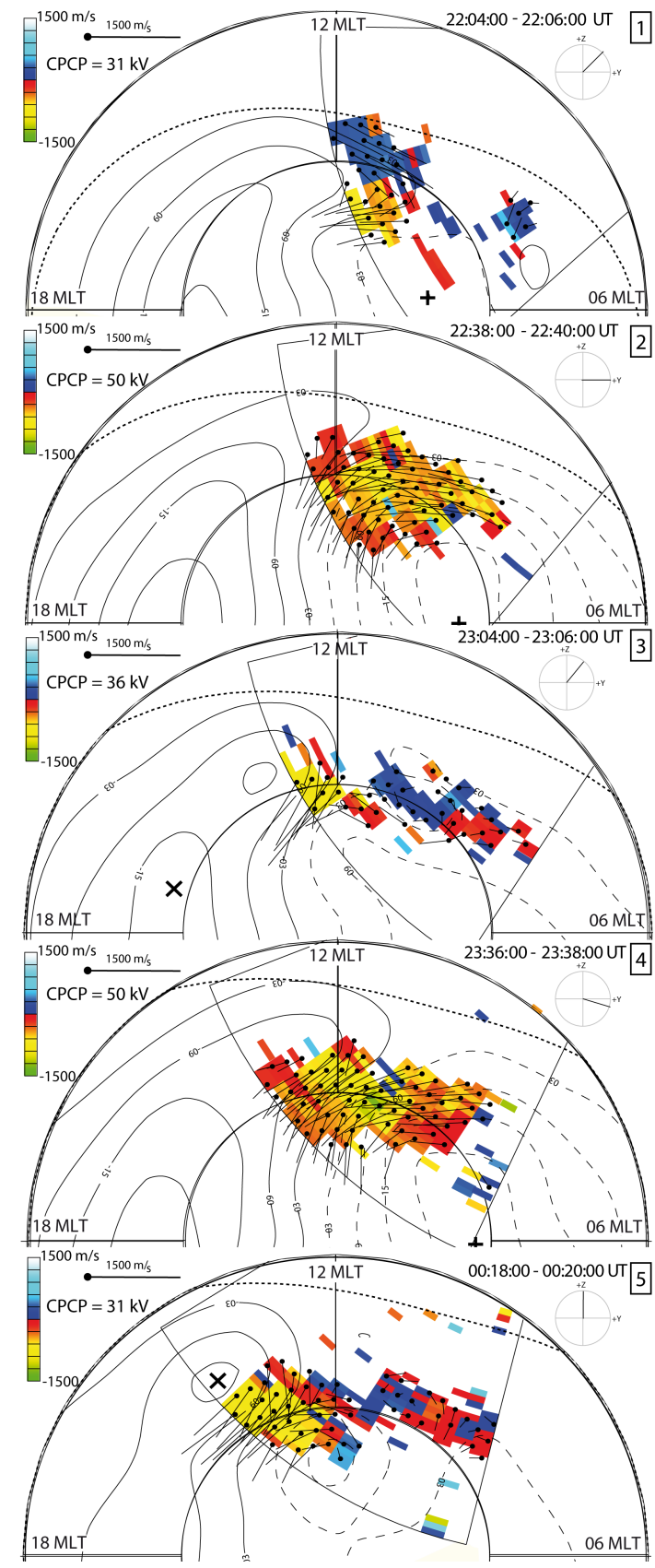

Fig. 6. Line of sight velocities measured by TIGER in the SH during five 2 min scans corresponding to different IMF conditions. The outer (inner) circle indicates $-70^{\circ}\left(-80^{\circ}\right)$ MLAT. The TIGER field of view and convection maps with computed vector velocities are overlaid to each panel: the solid (dashed) curves indicate negative (positive) potential isocontours, while the dotted line indicates the Heppner-Maynard boundary. The top left corner of each map shows: a palette according to which velocities are colour coded, the cross polar cap potential (CPCP); a $1500 \mathrm{~m} / \mathrm{s}$ vector according to which all vector lengths are scaled. The right hand top corner of each map shows the start and end times and a small inset indicating the IMF direction (according to Table 1) in the $B_{y}-B_{z}$ GSM plane.

\section{Effects of the IMF rotations on SH convection}

As we remarked already in Sect. 3, only TIGER data are available in the SH day side. Therefore, we visually inspected all 2-min FOV plots of the TIGER $V_{\mathrm{LOS}}$ for the whole period under study. We will not show and describe all such plots, but we concentrate on five of them, which are contained as individual panels in Fig. 6 and display $V_{\text {LOS }}$ as colour coded cells plotted in polar coordinates between $-70^{\circ}$ and $-90^{\circ}$ MLAT and from 06:00 to 18:00 MLT. In such a representation the Sun is at the top, the radar site is outside the figure in the morning quadrant, at $-55.31^{\circ}$ MLAT and $133.96^{\circ}$ West geomagnetic longitude, the radar FOV is indicated by a fan bounded by black solid lines, and velocities towards (from) the radar are positive (negative). Each panel is typical of one of the five periods defined in Fig. 1. In addition to the measured velocities, each panel also shows the potential isocontours calculated through the map potential software together with velocity vectors calculated at points where actual measurements are available. Such maps are built by making use also of the SuperDARN data which are available in the night side. However, as the maps on the day side are only based on TIGER data, we do not assign to them a quantitative meaning.

The top panel refers to the 22:04-22:06 UT interval, just before the A rotation, and displays a clear region of cells characterised by positive velocity between $\simeq-77^{\circ}$ and $\simeq-81^{\circ}$ MLAT and between 10:30 and 12:00 MLT, which is adjacent to a region at higher MLAT where velocities are negative. Further to such regions, some scattered velocities are present at lower MLT, heading towards the radar at lower MLAT and away from it at higher MLAT. Similar velocity patterns are observed by TIGER in all two-min intervals before the A rotation.

At the A rotation the situation changes and a new velocity pattern is attained within a few minutes. An example of the new pattern is shown in the second panel from the top which refers to the 22:38-22:40 UT interval, when the IMF clock angle was $\simeq 90^{\circ}$ MLAT. In this case we see that practically all measured velocities are directed away from the radar. Moreover, the number of back-scattering cells has considerably increased, by roughly a factor 2 .

At the $\mathrm{B}$ rotation the situation changes again, but the old velocity pattern persists for several minutes, and a new one emerges starting from 22:58 UT, until a clear region of positive velocity is set up between $\simeq-77^{\circ}$ and $\simeq-80^{\circ}$ MLAT between 09:00 and 11:30 MLT, which is surrounded by two regions of negative velocity at smaller and larger MLT, as shown in the third panel from the top (23:04-23:06 UT). At the same time the number of echoes observed in the TIGER FOV drastically drops. We also notice that the map potential software reconstructs, during several 2 min scans, a small clockwise cell in the dawn quadrant, centred at 11:00 MLT and $-82^{\circ}$ MLAT. 
A new clear change of velocity pattern occurs immediately after the $\mathrm{C}$ rotation, as shown by the fourth panel from the top, which refers to the 23:36-23:38 UT interval, when the IMF clock angle and that measured in the magnetosheath by Cluster 2 were both $\simeq 90^{\circ}$. Again, as for the 22:38-22:40 UT interval, the measured velocities are almost all directed away from the radar and are consistent with the new IMF orientation, while the number of echoes has roughly doubled again.

Finally, at the $\mathrm{D}$ rotation the last change of pattern takes place. Again the reconfiguration in the SH starts at 00:12 UT, 8 min later than in the $\mathrm{NH}$, until a region of positive velocities sets up around 11:00 MLT, similarly to what was observed after the B rotation. The decrease of the number of echoes occurs again, although not so dramatically as for the B rotation. Again the map potential software reconstructs a small clockwise cell in the dawn quadrant.

In conclusion, we may state that: 1) as a consequence of each of the four IMF rotations, the TIGER $V_{\text {LOS }}$ displays signatures which can be interpreted as due to convection reconfigurations; 2) more radar echoes are observed in the TIGER FOV for $B_{z}<0$ or for dominant $B_{y}$ than for $\left.B_{z}>0 ; 3\right)$ after rotations $\mathrm{A}$ and $\mathrm{C}$ the reconfiguration starts within a few minutes, as in the $\mathrm{NH}$, while after rotations $\mathrm{B}$ and $\mathrm{D}$ it starts several minutes later than in the $\mathrm{NH}$.

\section{Kodiak and TIGER $V_{\mathrm{LOS}}$ reversals}

In the preceding two sections, based on SuperDARN convection maps for the NH and on TIGER FOV plots for the $\mathrm{SH}$, we showed evidence that day side convection in both hemispheres reconfigured as a consequence of IMF rotations. Moreover, if we compare the reconfiguration times quoted for the NH in Sect. 4 and for the SH in Sect. 5, we notice that the reconfiguration seems to have occurred at different times in the two hemispheres at the two northward rotations of the IMF.

As we noticed already in the description of Figs. 2, 3, 4 and 5 , the $\mathrm{NH}$ reconfiguration always seems to start close to 12:00 MLT and at latitudes close or above $80^{\circ}$ MLAT. On the other hand, the change observed in Fig. 6 in relation to the IMF rotations regarded the sign of $V_{\text {LOS }}$ close to $-80^{\circ}$ MLAT and between 10:30 and 12:00 MLT. This suggests that, in order to summarise the information on reconfiguration times with a single figure, it is worthwhile examining directly $V_{\text {LOS }}$ as measured by single radars in such MLATMLT regions.

We recall that the bottom panels of Figs. 2, 3, 4 and 5 and all panels of Fig. 6 show the FOV's of the Kodiak and TIGER radars superimposed on the $\mathrm{NH}$ and $\mathrm{SH}$ convection maps, respectively. $\mathrm{NH}$ data were also available from radars other than Kodiak and were used in the reconstruction of the potential maps; however, it appears that the Kodiak FOV was roughly pointing towards the north magnetic pole close to the noon MLT meridian. For the Kodiak data around noon MLT positive velocities (towards the radar) correspond to sunward flows (from the polar cap to lower MLAT) and negative velocities (away from the radar) correspond to tailward flows (from low latitudes towards the polar cap). On this basis, we expect to see signatures of the flow reconfigurations in the time series of Kodiak $V_{\mathrm{LOS}}$ near noon MLT, i.e. normal convection cells should yield negative velocities and reverse cells should yield positive velocities.

As regards the $\mathrm{SH}$, the TIGER FOV was on average at a $60^{\circ}$ angle from noon MLT during the A rotation and at about $30^{\circ}$ during the $\mathrm{D}$ rotation. As a consequence, one can expect that signatures of reconfigurations, in the form of $V_{\mathrm{LOS}}$ reversals, should show up as well in the time series of TIGER $V_{\text {LOS }}$ near noon MLT and should be more and more evident as the angle between the TIGER beams and the 12:00 MLT meridian decreases.

Concerning the examination of $V_{\mathrm{LOS}}$ as a function of time, a further problem stems from the fact that each radar beam samples different MLT's as a function of time. In order to remove this ambiguity, we considered the 11:00-12:00 MLT sector and two $2^{\circ}$ MLAT bins, from $78^{\circ}$ to $80^{\circ}$ MLAT in the $\mathrm{NH}$ and from $-78^{\circ}$ to $-80^{\circ}$ MLAT in the $\mathrm{SH}$, we excluded ground scatter and all echoes having a reflected power $<3 \mathrm{~dB}$ and averaged $V_{L O S}$ for each 2 min interval. In this way we produced two time series of $V_{\mathrm{LOS}}$, which we will call hereafter $V_{T}$ for TIGER and $V_{K}$ for Kodiak.

Figure 7, in its upper panel, displays $V_{T}$ and $V_{K}$ from 22:00 UT, 2 January 2003, to 00:30 UT, 3 January 2003, thus including the A, B, C and D IMF rotations (marked with vertical dashed lines). Moreover, the lower panel of Fig. 7 displays the number of valid echoes (i.e. excluding ground scatter and reflected power $<3 \mathrm{~dB}$ ) over the whole TIGER and Kodiak FOV's, indicated by $N_{T}$ (black solid line) and $N_{K}$ (black dashed line), respectively. As during the whole event, the Kodiak and TIGER radars operated with 1 and 2 min resolution, respectively, the number of Kodiak echoes has been divided by 2 .

It appears that both $V_{T}$ and $V_{K}$ in Fig. 7 alternate between positive and negative values. In particular, as regards $V_{T}$ three "positive" periods are seen with average values ranging from $300 \mathrm{~m} / \mathrm{s}$ to $150 \mathrm{~m} / \mathrm{s}$ and with oscillations of the order of $50 \mathrm{~m} / \mathrm{s}$, while in the two "negative" periods the average values range from -300 to $-700 \mathrm{~m} / \mathrm{s}$, with oscillations usually of the order of $100 \mathrm{~m} / \mathrm{s}$ (apart from one large oscillation which reaches a peak-to-peak value of $500 \mathrm{~m} / \mathrm{s}$ around 22:50 UT). A similar behaviour is displayed by $V_{K}$, with "positive" averages ranging from 500 to $100 \mathrm{~m} / \mathrm{s}$, while the "negative" averages are -400 and $-500 \mathrm{~m} / \mathrm{s}$; in this case the oscillations are somewhat larger, i.e. $100-500 \mathrm{~m} / \mathrm{s}$ peakto peak. However, the maxima of both $V_{T}$ and $V_{K}$ during the "negative" periods fall well below (by a few hundred $\mathrm{m} / \mathrm{s}$ ) the minima of the "positive" periods. We interpret the positive values of $V_{T}$ and $V_{K}$ in terms of flow separating two reverse cells characteristic of lobe reconnection due to a northward IMF, and the negative values as anti-sunward flow towards 


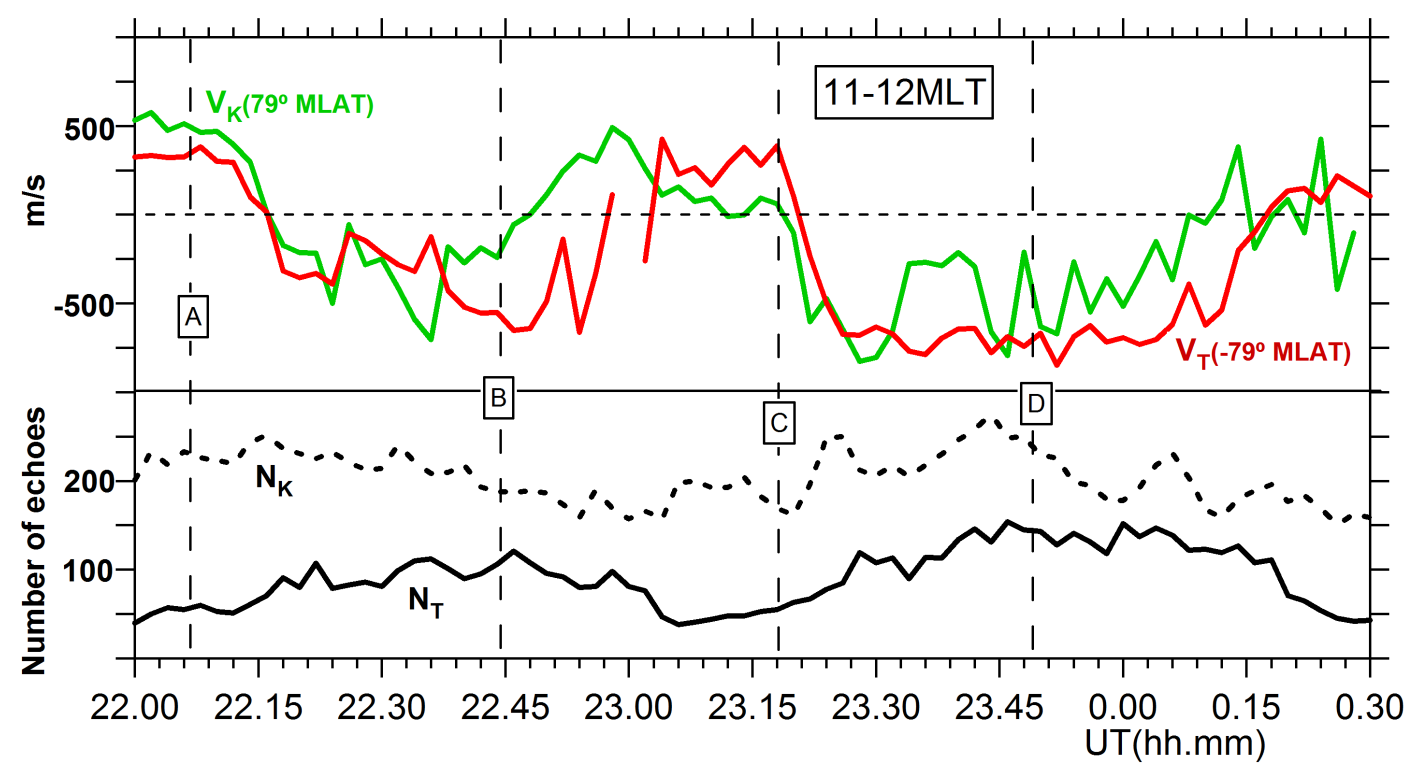

Fig. 7. Upper panel: 11-12 MLT line of sight velocities as a function of time in two $2^{\circ}$ MLAT bins, centred at $79^{\circ}$ MLAT and at $-79^{\circ}$ MLAT, for Kodiak ( $V_{K}$ in green) and TIGER ( $V_{T}$ in red) radars, respectively. Lower panel: number of radar echoes over the whole TIGER and Kodiak fields of view, indicated by $N_{T}$ and $N_{K}$, respectively $\left(N_{K}\right.$ divided by 2 to account for the 1 min resolution of Kodiak, compared with the TIGER 2 min resolution). The vertical dashed lines mark the A, B and C IMF rotations and the start of the D rotation (see Fig. 1).

the polar cap between two normal convection cells for dominant $B_{y}$. In fact, in the upper panel we notice that both $V_{T}$ and $V_{K}$ reverse, from positive to negative values, roughly at the same time, around 22:15 UT, about $8 \mathrm{~min}$ after the A rotation, and around 23:21 UT, about 3 min after the C rotation. On the contrary, $V_{K}$ reverses from negative to positive at 22:48 UT, 4 min after the B rotation, about 15 min prior to the reversal experienced by $V_{T}$. Later on $V_{K}$ turns positive about $18 \mathrm{~min}$ after the nominal $\mathrm{D}$ rotation, about $12 \mathrm{~min}$ prior to $V_{T}$.

Turning to the lower panel, we already noticed, from the visual inspection of all TIGER FOV's and convection maps, that the number of echoes appears to depend on the IMF orientation. In fact, we see that, although $N_{T}$ undergoes variations of the order of 10-40 echoes from time to time, $N_{T} \simeq 50$ during the periods of northward IMF and $N_{T} \simeq 100-150$ during the $B_{y}$ dominated periods. It also appears that, after the $\mathrm{A}$ and $\mathrm{C}$ rotations, $N_{T}$ increases 69 min after the nominal rotation time, while, after the B and D rotations, $N_{T}$ decreases $15-20$ min after the nominal rotation time; i.e. the time lags between the IMF rotations and the main $N_{T}$ changes are essentially the same as those between IMF and $V_{T}$. A quantitative way to describe this is to consider the cross correlation between $N_{T}$ and $V_{T}$. This calculation yields that the linear correlation coefficient between $N_{T}$ and $V_{T}$ has a maximum value of -0.86 for a time lag of 2 min. A behaviour similar to that of $N_{T}$ can also be recognised in the $N_{K}$ plot: in fact, a minimum $\left(N_{K} \simeq 150\right)$ can be identified between rotations $\mathrm{B}$ and $\mathrm{C}$ and after rotation $\mathrm{D}$, and a maximum $\left(N_{K} \simeq 270\right.$ ) occurs before rotation D. However, no clear change of $N_{K}$ occurs at the A rotation and $N_{K}$ displays larger short lived excursion from the average trend than $N_{T}$. Therefore, we must conclude that in this case the correlation is worse, as it is confirmed quantitatively by the fact that the best linear correlation coefficient between $N_{K}$ and $V_{K}$ is -0.37 for a -4 min lag.

\section{Discussion}

In Sects. 4 and 5 we made use of SuperDARN observations to describe the response of day side ionospheric convection to four IMF rotations (see Fig. 1), during which the IMF flipped between a mainly $B_{z}>0$ orientation and a mainly $B_{y}>0$ with $B_{z} \simeq 0$ orientation, while $B_{x}$ was always negative. As it was remarked in Sect. 2, the IMF rotations were accompanied by variations of the solar wind dynamic pressure, which overall increased from 5.52 to $11.1 \mathrm{nPa}$ from the start to the end of the period under study. Newell and Meng (1994) showed that, when $P_{\text {dyn }}<2 \mathrm{nPa}$, the NH cusp is located on average about noon MLT and $80^{\circ}$ MLAT with widths of 01:00 MLT and $3^{\circ}$ MLAT, while, when $P_{\mathrm{dyn}}>$ $4 \mathrm{nPa}$, it is located on average about noon MLT and $78^{\circ}$ MLAT with widths of 03:00 MLT and $9^{\circ}$ MLAT. This statistical behaviour suggests that an increased solar wind dynamic pressure favours the transfer of mass and energy through the magnetopause; this, in turn, should result in enhanced ionospheric convection. On these grounds, we do not expect that at rotations $\mathrm{B}$ and $\mathrm{D}$ the dynamic pressure played 
a role in determining the different reconfiguration times observed in the two hemispheres. This consideration is justified by the fact that the pressure behaved differently at such two rotations: in fact, at rotation B it decreased slightly from 7.9 to $6.7 \mathrm{nPa}$ to start increasing again after a few minutes, while during the long D rotation it only increased moderately from 8.8 to $9.7 \mathrm{nPa}$. A similar pressure increase, from 8.1 to $9.0 \mathrm{nPa}$, was observed at rotation $\mathrm{C}$, but in this case no time lag occurred between the $\mathrm{NH}$ and $\mathrm{SH}$ reconfigurations. Finally, the largest effect on ionospheric convection during the whole period under study should be expected at rotation A, at which the pressure jumped from 5.1 to $8.1 \mathrm{nPa}$; however, we can notice that, if we compare the $\mathrm{NH}$ and $\mathrm{SH}$ reconfigurations at rotation $\mathrm{A}$ with those at rotation $\mathrm{C}$, no important difference is seen, as regards both their morphologies and their timings. In conclusion, it seems reasonable to conclude that the dynamic pressure does not play a significant role in determining the convection reconfiguration times during this event. On the other hand, it cannot be excluded that such a role could be important in other events which display dynamic pressure changes in combination with IMF rotations.

In the NH the SuperDARN data coverage was extensive enough to base the description of the convection reconfiguration on the maps obtained through the map potential technique, while in the $\mathrm{SH}$ we made use of individual plots of the TIGER $V_{\text {LOS. }}$. Moreover, in Sect. 6 we further investigated such response by considering $V_{\text {LOS }}$ 's measured in the two hemispheres in two nominally conjugated regions between 11 and 12 MLT. We found that the two hemispheres display similarities and differences which need to be commented upon and discussed.

\section{1 $\quad B_{y}>0$ convection patterns}

We discuss first the observed topology of the patterns for the IMF $B_{y}>0$ dominated configuration, i.e. after rotations A and $C$ and prior to rotations $B$ and D. In all such cases the $\mathrm{NH}$ pattern was dominated by a large clockwise cell extending from the dusk side to the dawn side (Cowley and Lockwood, 1992). For the SH we notice that the TIGER $V_{\mathrm{LOS}}$ was consistent with the presence of a duskward-tailward flow between $76^{\circ}$ and $82^{\circ}$ MLAT; at the same time the data provided by the night side SuperDARN radars complemented the morning side measurements by TIGER, so that the map potential software steadily reconstructed a large counterclockwise cell on the morning side, extending partly to the dusk side, characterised by a smaller clockwise cell (see panels 2 and 4 from the top of Fig. 6). The obvious interpretation of these patterns is that they are generated by $B_{y}>0$ day side reconnection, that pulls reconnected field lines from dusk to dawn in the $\mathrm{NH}$ and from dawn to dusk in the SH. Nothing more can be said about further features of the SH pattern due to the paucity of the data. On the contrary, the NH patterns also showed evidence of secondary cells, similarly to what was already observed by other authors. In this regard, we re- call that a smaller dawn side counter-clockwise cell was often observed in the NH, sometimes completely formed, other times only partially resolved due to the incomplete MLT and MLAT coverage. In two cases we also observed three cell structures, i.e. at 22:18-22:20 UT (Fig. 2) and at 22:4622:48 UT (Fig. 3), which seem to match the model of Reiff and Burch (1985). To this regard, we also remark that the 22:18-22:20 UT three cell pattern developed from the four cell pattern of 22:06-22:08 UT through the 22:10-22:12 UT map. This sequence of convection maps resembles closely the past observations by Huang et al. (2000b), who observed that, as IMF $B_{y}$ became more dominant, the reverse cells shifted in MLT, reducing the size of one of the cells until a three-cell convection pattern developed.

\section{2 $\quad B_{z}>0$ convection patterns}

Under $B_{z}>0$ conditions, i.e. prior to rotation $\mathrm{A}$, between rotations $\mathrm{B}$ and $\mathrm{C}$ and after rotation $\mathrm{D}$, in general the $\mathrm{NH}$ patterns show signatures of two large reverse cells (see e.g. Milan et al., 2000; Huang et al., 2000a). Prior to the first rotation, such cells are both clearly reconstructed, while in the other cases the dusk counter-clockwise cell is not completely formed and the dawn cell can only be inferred from the general shape of convection. We explain such a pattern as due to high latitude lobe reconnection as expected for a mainly northward IMF. However, we recall that a low latitude dawnward flow, mainly across the noon MLT meridian, is always present, with variable intensity and, at times, with a tailward component. This flow coexists with lobe cells, even when two such cells are clearly observed at the same time, and can be interpreted as a distortion of the reverse convection pattern due to the prevailing positive $B_{y}$; on the other hand, it could also be that, as $B_{y}$ is steadily positive, the lobe reconnection line extends to the day side, duskward of the cusp (see e.g. Sandholt et al., 2003). Finally, we remark that, prior to rotation A, for several minutes, as illustrated in Fig. 2 in the 22:06-22:08 UT panel, we observed clear signatures of a four cell system, composed of two central reverse cells (roughly symmetric relative to noon MLT) accompanied by two lower latitude viscous cells as suggested by Reiff and Burch (1985) and observed by Huang et al. (2000a).

As regards the $\mathrm{SH}$, careful visual inspection of all TIGER FOV plots showed that the velocity patterns under $B_{z}>0$ conditions are very different from those seen under dominant $B_{y}>0$ conditions. This is evident from panels 1, 3 and 5 of Fig. 6, which are typical of the periods before rotation $A$ and $C$ and after rotation D. In all three periods TIGER observes both positive and negative $V_{\mathrm{LOS}}$ : in panels 3 and 5 the positive $V_{\text {LOS }}$ 's form two spots at dawn roughly at the same MLT and MLAT; in panel 1 they form a spot closer to 12:00 MLT. The three spots can be interpreted as signatures of flow moving from high to low latitude, i.e. with a sunward component. Moreover, in panels 3 and 5 the positive $V_{\mathrm{LOS}}$ spot occurs between two negative $V_{\mathrm{LOS}}$ spots, at dawn and 
dusk of it, respectively, which are compatible with the signature of two reverse lobe cells. Such a signature is not seen in panel 1, which only displays sparse echoes in the rest of the dawn quadrant and none at all in the dusk quadrant. Although the data coverage is low, it is clear that the TIGER observations under $B_{z}>0$ conditions are very different from those pertaining to dominant $B_{y}>0$ conditions. In conclusion, we suggest that both in the $\mathrm{NH}$ and in the SH reverse lobe cells are formed under $B_{z}>0$ conditions, although for the $\mathrm{SH}$ the evidence is not so compelling as for the $\mathrm{NH}$.

\subsection{Relation between the number of radar echoes and IMF orientation}

We shall now discuss the result shown in the bottom panel of Fig. 7, concerning the evolution of the number of echoes observed in the TIGER and Kodiak FOV's as a function of IMF orientation.

Other authors have discussed in the past the rate of occurrence of SuperDARN backscatter as a function of season, MLT, MLAT and geomagnetic activity. For our purposes it is useful to cite Ruohoniemi and Greenwald (1997), who described a marked seasonal effect in the rate of backscatter, found that such rates are much lower in summer than in winter, and "attributed this dependence to the suppression of density gradients by more intense photoionisation in summer". These remarks were confirmed, among others, by Milan et al. (1997), and by Vickrey and Kelley (1982) and Kelley et al. (1982), who noticed that increased conductivity in the E layer due to summer insolation can favour the decay of F-region density gradients. We rest on such considerations to explain why, in our case, TIGER observes a much smaller number of echoes than Kodiak throughout the event: the TIGER FOV is constantly illuminated by sunlight, so that day side ionisation smooths out the ionospheric density irregularities. Conversely, the Kodiak FOV is constantly beyond the day-night terminator, where density irregularities are much more probable and long lived.

Moving to the issue of the dependence of the rate of scatter on the IMF orientation, we recall that Ballatore et al. (2000) argued that reconnection at the magnetopause yields an increase of ionospheric irregularities, which are responsible for the generation of HF backscatter. It is by this same argument that we may try to address the different behaviour of $N_{T}$ and $N_{K}$ in response to the IMF rotations, as evidenced in Fig. 7. Starting from the Kodiak radar, we notice that the conditions were favourable to HF backscatter as in its FOV more than 150 echoes were observed throughout the event. In particular, about 200 echoes were observed already at the beginning of the event, under positive $B_{z}$ conditions, when particle precipitation probably occurred along field lines due to both lobe reconnection and to low latitude reconnection associated to the large positive $B_{y}$ component (as argued in the preceeding subsection). It is not inconceivable that, in such a situation, strong precipitations associated to reconnection might pro- duce two competing effects in the ionosphere: on one side to increase the density irregularities in the F-region, on the other side to worsen the local propagation conditions. As a result, as we remarked already in Sect. 6, the total number of echoes observed by Kodiak in its FOV, $N_{K}$, does not change as much as for TIGER during the event; moreover, although a dependence of $N_{K}$ on the IMF orientation is observed, this is less clear than for $N_{T}$.

The situation is different for the TIGER FOV. In this case the number of echoes is around 50 under positive $B_{z}$ conditions and around 100-150 under $B_{y}$ dominated conditions and displays time variations anti-correlated (with a -0.86 correlation coefficient at $2 \mathrm{~min}$ lag) with those of $V_{T}$ displayed in the upper panel of Fig. 7. Actually, $N_{T}$ is not equivalent to $V_{T}$, as $N_{T}$ pertains to the whole TIGER FOV, while $V_{T}$ pertains to a limited region, between 11:00 and 12:00 MLT and $-78^{\circ}$ and $-80^{\circ}$ MLAT. Therefore, for this event we take $N_{T}$ as an additional indicator of the SH reconfiguration.

If we look back at panel 1 of Fig. 6, we see that most echoes concentrated in two small MLT-MLAT spots between 11:00 and 12:00 MLT, with positive and negative velocities. It is natural to interpret such echoes as due to local irregularities caused by particle precipitation along field lines from a lobe reconnection site close to the southern cusp, as this is the only place in the TIGER FOV where irregularities are likely to occur under the present conditions of solar illumination. The problem may be posed of whether lobe reconnection occurs at all at the southern magnetopause under the given conditions, as the dipole tilt should favour the SH hemisphere, but the negative IMF $B_{x}$ component could favour the NH instead. We do not have any means of checking this directly, as no low altitude spacecraft was flying at the right place at this particular time, while the Cluster fleet was on an outbound orbit in the northern magnetosphere. However, we made use of the Cooling et al. (2001) model to check the probability that component merging may take place tailward of the southern cusp and found that a small SH lobe merging line could develop for all the positive $B_{z}$ conditions present during our event. Actually, we ran the Cooling model for the $\mathrm{NH}$ too and found that lobe reconnection is more probable there.

Following this line of thought, we can proceed to interpret the increase of $N_{T}$ which occurs between 22:12 and 22:18 UT. We suggest that the SH convection reconfigures after the A rotation and a dawn side low latitude merging line sets up, as expected for dominating $B_{y}>0$. Under these conditions the increase of the number of echoes is just the effect of the increased reconnection at low latitude (Ballatore et al., 2000). The same should apply to the increase observed soon after the $\mathrm{C}$ rotation. On the opposite, the decrease of $N_{T}$ observed after the B and D rotations can be interpreted in terms of the switching off of the low latitude reconnection with the simultaneous start of a weak lobe reconnection. 
Table 2. Start and End times of NH and SH convection reconfigurations following the A, B, C and D IMF rotations. Derived delays between start times are also listed (see text for details).

\begin{tabular}{cccccc}
\hline rot. (UT) & NH Start(UT) & NH End(UT) & SH Start(UT) & SH End(UT) & $\Delta$ Start(min) \\
\hline A 22:08 & $22: 08$ & $22: 14$ & $22: 08$ & $22: 14$ & 0 \\
C 23:18 & $23: 18$ & $23: 24$ & $23: 18$ & $23: 22$ & 0 \\
B 22:45 & $22: 45$ & $23: 02$ & $22: 58$ & $23: 04$ & 13 \\
D 23:55 & $00: 04$ & $00: 18$ & $00: 12$ & $00: 20$ & 8 \\
\hline
\end{tabular}

\subsection{NH and SH reconfiguration times}

Early models and observations suggested that IMF rotations cause the reconfiguration of ionospheric convection on time scales of tens of minutes starting from the noon sector (Lockwood et al., 1986; Todd et al., 1988; Saunders et al., 1992).

In Sects. 4 and 5 we suggested that, during the period that we have analysed, the time it takes for the convection maps to respond to an IMF rotation and to reconfigure depends both on the IMF and on the hemisphere and is larger for the $\mathrm{SH}$ when the IMF rotates from dominant $B_{y}>0$ to $B_{z}>0$. Before further discussing this suggestion, it is necessary to comment on the doubts that could be raised about it due the scarcity of $\mathrm{SH}$ data, as, in principle, we cannot totally exclude that reconfiguration started in the $\mathrm{SH}$ at an earlier time at a different MLAT-MLT location and then suddenly, i.e. within less than $1 \mathrm{~min}$, moved to the place where TIGER actually detected it. To this regard, we recall that negative $V_{\text {LOS's }}$ (i.e. duskward-tailward) were observed by TIGER over an extended MLAT-MLT region both before rotations $\mathrm{B}$ and $\mathrm{D}$, and after such rotations, for several minutes, at times when the NH reconfiguration had already clearly started; moreover, the reconfiguration was observed in the TIGER data roughly at the centre of the existing region of tailward-duskward flow, roughly at the location where one would expect the formation of a new lobe merging line under the current IMF conditions, both according to the general picture of ionospheric convection and according to the calculations we made through the Cooling et al. (2001) model (see Sect. 7.3). Therefore, it is natural to interpret the observations in terms of a $\mathrm{SH}$ reconfiguration actually starting first where TIGER actually saw it.

To complement the considerations on reconfiguration times based on NH convection maps and on SH TIGER FOV plots of $V_{\mathrm{LOS}}$, in Sect. 6 we looked at $V_{\mathrm{LOS}}$ 's reversals observed near noon MLT in the NH and in the SH by the Kodiak and the TIGER radar respectively and found that: 1) the IMF rotations towards $B_{y}$ dominated are accompanied by simultaneous $\mathrm{NH}$ and $\mathrm{SH}$ fast reconfigurations within a few minutes after the nominal IMF rotation; 2) the response to IMF northward rotations is slower, by several minutes; 3 ) the response to IMF northward rotations occurs in the NH about 813 min earlier than in the $\mathrm{SH}$. Such results must be regarded as additional evidence of the validity of the interhemispheric reconfiguration times evaluated on the basis of convection maps and TIGER FOV plots. Unfortunately, the Sect. 6 analysis could not be extended quantitatively to other MLT's and MLAT's because of the presence of gaps, especially in the $\mathrm{SH}$ data. However, as we discussed in Sect. 7.3, a support to our interpretation of the reconfiguration times comes also from the time evolution of the $N_{T}$ and $N_{K}$ parameters, which display a behaviour anticorrelated to that of $V_{T}$ and $V_{K}$.

Table 2 summarises our observations based on convection maps and TIGER FOV plots of $V_{\text {LOS }}$. The two top lines refer to the $\mathrm{A}$ and $\mathrm{C}$ rotations, when the IMF turned from $B_{z}>$ $B_{y}>0$ to $B_{y}>\left|B_{z}\right|$, while the two bottom lines refer to the opposite IMF rotations, B and D. For each rotation Table 2 shows the start and end times of reconfiguration in the $\mathrm{NH}$ and in the $\mathrm{SH}$, together with the delay between the $\mathrm{NH}$ and SH start times, $\Delta$ Start. As the time resolution is much higher for the IMF than for SuperDARN maps, we do not assign an error to the $\mathrm{A}, \mathrm{B}$ and $\mathrm{C}$ times. As regards rotation $\mathrm{D}$, we selected the start of the rotation which we know lasted for $20 \mathrm{~min}$. As the times under the Start and End headings were determined from convection maps in Sects. 4 and 5, they should all be assigned a 2-min error. As a consequence, $\Delta$ Start's should be assigned a maximum 4-min error.

It appears that for the $\mathrm{A}$ and $\mathrm{C}$ rotations the start times of the reconfigurations were very similar for the $\mathrm{NH}$ and for the $\mathrm{SH}$, within $2 \mathrm{~min}$. Moreover, the reconfigurations seem to have started at the nominal IMF rotation time. To this regard, we recall that the timing of the A and C IMF turnings can be affected by large errors, as we noted in the presentation of Fig. 1. Finally, we remark that the reconfiguration times were rather fast, on the order of $6 \mathrm{~min}$, suggesting that the low latitude $B_{y}$ driven reconnection starts roughly at the same time in both hemispheres and influences very rapidly the whole day side ionosphere. This result seems to agree with the observations by Ruohoniemi and Greenwald (1998) and Shepherd et al. (1999), who showed cases when the reconfiguration from strong northward IMF convection to strong southward IMF convection occurred in 2-4 min simultaneously at all MLT's extending from noon to midnight.

Regarding the B and D IMF rotations, it appears that the time response is quite different for the $\mathrm{NH}$ and the $\mathrm{SH}$. In fact, we observe that in the $\mathrm{SH}$ the reconfiguration starts considerably after the IMF nominal rotation (13 and $17 \mathrm{~min}$ for rotation $\mathrm{B}$ and $\mathrm{D}$ respectively) and lasts on the order of 
6-8 min. Conversely, in the NH the reconfiguration starts earlier ( 0 and $9 \mathrm{~min}$ after the IMF nominal time for rotations $\mathrm{B}$ and $\mathrm{D}$ respectively), but lasts much longer, 14-17 min, so that the SH completes the reconfiguration only a few minutes after the NH. This result is compatible with earlier findings by Taylor et al. (1998), who used NH SuperDARN convection velocities to show that sunward flows appeared in the noon sector within 2 min following an IMF northward turning and that the global flow completely reconfigured in $20 \mathrm{~min}$, and by Huang et al. (2000a), who found that the NH reverse convection cells form within $\simeq 12$ min after a northward turning of the IMF. In conclusion, the new result of our work is the late start and the faster reconfiguration observed in the $\mathrm{SH}$ at rotations $\mathrm{B}$ and $\mathrm{D}$.

We summarise the sequence of events observed for both the $\mathrm{B}$ and the D rotations: 1) appearance in the $\mathrm{NH}$ of a clockwise cell centred at 10:00-10:30 MLT and 82 ${ }^{\circ}$ MLAT; 2) strengthening of the new $\mathrm{NH}$ cell; 3) appearance in the $\mathrm{NH}$ of a sunward flow channel from the polar cap (bending towards dawn at or below $80^{\circ}$ ); 4) sudden reconfiguration of the SH pattern with the appearance of a flow from high to low latitude between 11:00 and 12:00 MLT; 5) completion of the $\mathrm{NH}$ reconfiguration and, within minutes, appearance of SH signatures of two reverse cells.

To this regard, we recall that, as this event occurred in winter time, the magnetic dipole tilt should favour lobe reconnection in the $\mathrm{SH}$; however, a large $B_{x}$ is believed to alter this seasonal effect (Cowley, 1983; Crooker and Rich, 1993; Lockwood and Moen, 1999). This is exactly the case for the event that we have described in this work, as at rotation B ACE $B_{x}$ changed from $\simeq-3 \mathrm{nT}$ to $\simeq-10 \mathrm{nT}$ and at rotation $\mathrm{D}$ it changed from $\simeq-3 \mathrm{nT}$ to $\simeq-7 \mathrm{nT}$, while both at B and D ACE $B_{z}$ changed from $\simeq-3 \mathrm{nT}$ to $\simeq 10 \mathrm{nT}$ and $B_{y}$ changed from $\simeq 10 \mathrm{nT}$ to $\simeq 0 \mathrm{nT}$. As a last remark, it is worth recalling that, following Østgaard et al. (2005), for a northward IMF, positive IMF $B_{x}$ "may cause reconnection to occur first and more efficiently in the southern lobe". If we adopt this argument for our event, we must conclude that negative $B_{x}$ at the $\mathrm{B}$ and $\mathrm{D}$ rotations can be invoked to explain the fact that the ionospheric reconfiguration occurs in the NH earlier than in the SH. To this regard, we may also recall that Provan et al. (2005) argued that "reconnection in the unfavoured hemisphere may eventually be activated at a later stage, involving the overdraped magnetic flux." We are at present unable to estimate the time delay which we should expect in our event between northern and southern lobe reconnection and leave this investigation to a future study. However, we can also think of other possible causes of the observed delay. Firstly, one could think of different positions of the lobe reconnection site in the $\mathrm{NH}$ and SH which could yield two different propagation times of the magnetosheath plasma to each site. Secondly, we could think of asymmetric propagation of the plasma in the two hemispheres, e.g. with a plasma stagnation in front of the southern cusp indentation, which would lead to a longer travel time to the SH reconnection site. Thirdly, different conditions in the $\mathrm{NH}$ and $\mathrm{SH}$ ionospheres could yield different time responses to magnetopause reconnection. To this regard, throughout the event we have studied, the dayside ionospheric conductivity is certainly on average higher in the $\mathrm{SH}$ than in the $\mathrm{NH}$ ionosphere; however, it is not clear how such different conditions could be at work at rotations B and D of the IMF and not at rotations $\mathrm{A}$ and $\mathrm{C}$. The investigation of these possibilities goes beyond the aim of this paper.

\section{Summary and conclusions}

We studied high-latitude convection during an interval of prolonged IMF $B_{y}>0$ and found, as expected from previous works by other authors (Reiff and Burch, 1985), that the day side ionospheric convection is controlled by the IMF in both hemispheres.

For strongly northward IMF, we observed signatures of two reverse cells, both in the $\mathrm{NH}$ and in the $\mathrm{SH}$, with sunward flow over the polar cap due to reconnection occurring tailward of the cusps. On one occasion we also observed in the NH two viscous cells at the sides of the central reverse cell pair, i.e. a four cell pattern.

For a dominating duskward IMF, we observed: in the NH a large dusk cell, accompanied by a smaller dawn cell and, on two occasions, a three cell pattern, composed of a large clockwise cell and two viscous cells (Reiff and Burch, 1985); in the SH a dawn cell protruding to the dusk quadrant, and, in one case, a smaller dusk clockwise cell. To a zero order approximation the $\mathrm{NH}$ and the $\mathrm{SH}$ patterns appeared to be symmetric.

The timings of the $\mathrm{NH}$ and $\mathrm{SH}$ convection reconfiguration after each IMF rotation were studied by comparing single $\mathrm{NH}$ convection maps before and after the A, B, C and D rotations with all TIGER FOV plots of $V_{\mathrm{LOS}}$. This comparison showed that the convection reconfiguration from a $\theta \simeq 45^{\circ}$ to a $\theta \simeq 90^{\circ}$ pattern occurred almost simultaneously (i.e. within a few minutes) in the two hemispheres, as expected, because the magnetosheath draping over the day side magnetopause of a duskward IMF should give approximately simultaneous effects in the NH and SH.

On the contrary, we found that the reconfiguration from a $B_{y}$ dominated to a northward IMF pattern starts in the NH 813 min earlier than in the SH. However, it appears that in the $\mathrm{NH}$ the reconfiguration occurs more slowly than in the $\mathrm{SH}$ (14-17 min compared to 6-8 $\mathrm{min}$ ), so that eventually they are completed almost simultaneously.

We also studied the timing of convection reconfiguration between 11:00 and 12:00 MLT as seen by the NH Kodiak radar, between $78^{\circ}$ and $80^{\circ}$ MLAT, and as seen by the SH TIGER radar, between $-78^{\circ}$ and $-80^{\circ}$ MLAT, and found results compatible with the already mentioned global delay times. Moreover, we found that, for this period, the number of total echoes measured by TIGER in its FOV provides 
an additional means of evaluation of the $\mathrm{SH}$ reconfiguration times.

In order to explain the observed delay in starting the reconfiguration in the two hemispheres, we suggest that: a) due to the presence of a strong negative IMF $B_{x}$ component, a northward-tailward magnetosheath magnetic field starts reconnecting at the northern high latitude magnetopause, tailward of the cusp; b) the magnetic field is draped around the day side magnetopause; c) later on, the draped magnetic field reconnects at the high latitude southern magnetopause tailward of the cusp. Further to that, other contributions to the delay could be at play, e.g. asymmetric solar wind travel times in the $\mathrm{NH}$ and $\mathrm{SH}$ magnetosheath, asymmetric locations of the lobe reconnection sites, different conditions of the NH and SH ionosphere. The investigation of such possibilities lies beyond the aim of this paper.

The findings on different interhemispheric time responses to IMF rotations and on the $\mathrm{SH}$ variation of the backscatter rate with IMF orientation constitute the main and new results of this paper, which call for further studies based on similar events.

Acknowledgements. Ace data have been obtained from CDAWeb. We thank D. J. McComas and N. Ness for their use. This research has been partially supported by ASI contract N. I/035/05/0 and by P.N.R.A. TIGER has been supported by the Australian Research Council's Discovery Project DP0664424, the Australian Antarctic Science Program and the US Air Force Office of Scientific Research.

Topical Editor M. Pinnock thanks P. Ponomarenko and another anonymous referee for their help in evaluating this paper.

\section{References}

Amata, E., Ambrosino, D., Marcucci, M. F., and Coco, I.: Multiinstrument study of high latitude ionospheric convection during a positive By period, SIF, Conf. Proceedings, 11 Workshop Italian Research on Antarctic Atmosphere, edited by: Colacino, M. and Rafanelli, C., 79, 155-169, 2009.

Ballatore, P., Villain, J. P., Vilmer, N., and Pick, M.: The influence of the interplanetary medium on SuperDARN radar scattering occurrence, Ann. Geophys., 18, 1576-1583, 2000,

http://www.ann-geophys.net/18/1576/2000/.

Balogh, A., Dunlop, M. W., Cowley, S. W. H., Southwood, D. J., Thomlinson, J. G., Glassmeier, K. H., Musmann, G., Luhr, H., Buchert, S., Acuna, M. H., Fairfeld, D. H., Slavin, J. A., Riedler, W., Schwingenschuh, K., and Kivelson, M. G.: The Cluster Magnetic Field Investigation, Space Sci. Rew., 79, 65-91, 1997.

Burke, W. J., Kelley, M. C., Sagalyn, R. C., Smiddy, M., and Lai, S. T.: Polar cap electric field structures with a northward interplanetary magnetic field, Geophys. Res. Lett. 6, 21-24, 1979.

Chisham, G., Lester, M., Milan, S. E., Freeman, M. P., Bristow, W. A., Grocott, A., McWilliams, K. A., Ruohoniemi, J. M., Yeoman, T. K., Dyson, P. L., Greenwald, R. A., Kikuchi, T., Pinnock, M., Rash, J. P. S., Sato, N., Sofko, G. J., Villain, J.-P., and Walker, A. D. M.: A decade of the Super Dual Auroral Radar Network (Su-
perDARN): scientifc achievements, new techniques and future directions, Surv. Geophys., 28, 33-109, 2007.

Cooling, B. M. A., Owen, C. J., and Schwartz, S. J.: Role of magnetosheath flow in determining the motion of open flux tubes, J. Geophys. Res., 106, 18763-18775, 2001.

Cowley, S. W. H.: Interpretation of observed relations between solar-wind characteristics and effects at ionospheric altitudes, in: High Latitude Space Plasma Physics, edited by: Hultqvist, B. and Hagfors, T., 225-249, Plenum, New York, 1983.

Cowley, S. W. H. and Lockwood, M.: Excitation and decay of solar wind-driven flows in the magnetosphere-ionosphere system, Ann. Geophys., 10, 103-115, 1992.

Crooker, N. U. and Rich, F. J.: Lobe cell convection as a summer phenomenon, J. Geophys. Res., 98, 13403-13407, 1993.

Freeman, M. P., Farrugia, C. J., Burlaga, L. F., Hairston, M. R., Greenspan, M. E., Ruohoniemi, J. M., and Lepping, R. P.: The Interaction of a Magnetic Could With the Earth: Ionospheric Convection in the Northern and Southern Hemispheres for a Wide Range of Quasi-Steady Interplanetary Magnetic Field Conditions, J. Geophys. Res., 98, 7633-7655, 1993.

Greenwald, R. A., Baker, K. B., Dudeney, J. R., Pinnock, M., Jones, T. B., Thomas, E. C., Villain, J.-P., Cerisier, J.-C., Senior, C., Hanuise, C., Hunsucker, R. D., Sofko, G., Koehler, J., Nielsen, E., Pellinen, R., Walker, A. D. M., Sato, N., and Yamagishi, H.: DARN/SUPERDARN: A Global View of the Dynamics of HighLatitude Convection, Space Sci. Rev., 71, 761-796, 1995.

Heppner, J. P. and Maynard, N. C.: Empirical high-latitude electric field models, J. Geophys. Res. 92, 4467-4489, 1987.

Huang, C.-S., Sofko, G. J., Koustov, A. V., Andre, D. A., Ruohoniemi, J. M., Greenwald, R. A., and Hairston, M. R.: Evolution of ionospheric multicell convection during northward interplanetary magnetic field with $\left|B_{z} / B_{y}\right|>1$, J. Geophys. Res. 105, 27095-27107, 2000a.

Huang, C.-S., Murr, D., Sofko, G. J., Hughes, W. J., and Moretto, T.: Ionospheric convection response to changes of interplanetary magnetic field $\mathrm{Bz}$ component during strong $B_{y}$ component, J. Geophys. Res., 105, 5231-5243, 2000b.

Kamide, Y., Richmond, A. D., Emery, B. A., Hutchins, C. F., Ahn, B. H., de la Beaujardire, O., Foster, J. C., Heelis, R. A., Kroehl, H. W., Rich, F. J., and Slavin, J. A.: Groundbased studies of ionospheric convection associated with substorm expansion, J. Geophys. Res., 99, 19451-19466, 1994.

Kelley, M. C., Vickrey, J. F., Carlson, C. W., and Torbert, R.: On the origin and spatial extent of high-latitude $\mathrm{F}$ region irregularities, J. Geophys. Res., 87, 4469-4475, 1982.

Lockwood, M., van Eyken, A. P., Bromage, B. J. I., Willis, D. M., and Cowley, S. W. H.: Eastward propagation of a plasma convection enhancement following a southward turning of the interplanetary magnetic field, Geophys. Res. Lett., 13, 72-76, 1986.

Lockwood, M. and Moen, J.: Reconfiguration and closure of lobe flux by reconnection during northward IMF: possible evidence for signatures in cusp/cleft auroral emissions, Ann. Geophys., 17, 996-1011, 1999, http://www.ann-geophys.net/17/996/1999/.

Lu, G., Richmond, A. D., Emery, B. A., Reiff, P. H., de la Beaujardière, O., Rich, F. J., Denig, W. F., Kroehl, H. W, Lyons, L. R., Ruohoniemi, J. M., Friis-Christensen, E., Opgenoorth, H., Persson, M. A. L., Lepping, R. P., Rodger, A. S., Hughes, T., McEwin, A., Dennis, S., Morris, R., Burns, G., and Tomlinson, L.: Interhemispheric asymmetry of the high-latitude ionospheric 
convection pattern, J. Geophys. Res., 99, 6491-6510, 1994.

Milan, S. E., Yeoman, T. K., Lester, M., Thomas, E. C., and Jones, T. B.: Initial backscatter occurrence statistics from the CUTLASS HF radars, Ann. Geophys., 15, 703-718, 1997, http://www.ann-geophys.net/15/703/1997/.

Milan, S. E., Lester, M., Cowley, S. W. H., and Brittnacher, M.: Dayside convection and auroral morphology during an interval of northward interplanetary magnetic field, Ann. Geophys., 18, 436-444, 2000, http://www.ann-geophys.net/18/436/2000/.

Newell, P. T. and Meng, C.-I.: Ionospheric projection of magnetospheric regions under low and high solar wind pressure conditions, J. Geophys. Res., 99, 273-286, 1994.

Papitashvili, V. O., Belov, B. A., Faermark, D. S., Feldstein, Y. I., Golyshev, S. A., Gromova, L. I., and Levitin, A. E.: Electricpotential patterns in the northern and southern polar-regions paramaterized by the interplanetary magnetic field, J. Geophys. Res., 99, 13251-13262, 1994.

Provan, G., Lester, M., Grocott, A., and Cowley, S. W. H.: Pulsed flows observed during an interval of prolonged northward IMF, Ann. Geophys., 23, 1207-1225, 2005, http://www.ann-geophys.net/23/1207/2005/.

Reiff, P. H. and Burch, J. L.: IMF $B_{y}$-dependent flow and Birkeland currents in the day side magnetosphere. 2. A global model for northward and southward IMF, J. Geophys. Res., 90, 1595-1609, 1985.

Rich, F. J. and Hairston M.: Large-scale convection patterns observed by DMSP, J. Geophys. Res., 99, 3827-3844, 1994.

Ruohoniemi, J. M. and Greenwald, R. A.: Statistical patterns of high-latitude convection obtained from Goose Bay HF radar observations, J. Geophys. Res., 101, 21743-21763, 1996.

Ruohoniemi, J. M. and Greenwald, R. A.: Rates of scattering occurrence in routine HF radar observations during solar cycle maximum, Radio Sci., 32, 1051-1070, 1997.

Ruohoniemi, J. M. and Baker, K. B.: Large-scale imaging of highlatitude convection with Super Dual Auroral Radar Network HF radar observations, J. Geophys. Res., 103, 20797-20811, 1998.

Ruohoniemi, J. M. and Greenwald, R. A.: The response of highlatitude convection to a sudden southward IMF turning, Geophys. Res. Lett., 25, 2913-2916, 1998.

Ruohoniemi, J. M. and Greenwald, R. A.: Dependencies of high-latitude plasma convection: Consideration of interplanetary magnetic field, seasonal, and universal time factors in statistical patterns, J. Geophys. Res., 110, A09204, doi:10.1029/2004JA010815, 2005.
Sandholt, P. E., Moen, J., Farrugia, C. J., Cowley, S. W. H., Lester, M., Milan, S. E., Valladares, C., Denig, W. F., and Eriksson, S.: Multi-site observations of the association between aurora and plasma convection in the cusp/polar cap during a southeastward ( $B_{y} \sim\left|B_{z}\right|$ ) IMF orientation, Ann. Geophys., 21, 539-558, 2003, http://www.ann-geophys.net/21/539/2003/.

Saunders, M. A., Freeman, M. P., Southwood, D. J., Cowley, S. W. H., Lockwood, M., Samson, J. C., Farrugia, C. J., and Hughes, T. J.: Dayside ionospheric convection changes in response to long period IMF oscillations: Determination of the ionospheric phase velocity, J. Geophys. Res., 97, 19373-19380, 1992.

Shepherd, S. G., Greenwald, R. A., and Ruohoniemi, J. M.: A possible explanation for rapid, large-scale ionospheric responses to southward turnings of the IMF, Geophys. Res. Lett., 26, 31973200, 1999.

Shepherd, S. G. and Ruohoniemi, J.: Electrostatic potential patterns in the high-latitude ionosphere constrained by SuperDARN measurements, J. Geophys. Res., 105, 23005-23014, 2000.

Taylor, J. R., Cowley, S. W. H., Yeoman, T. K., Lester, M., Jones, T. B., Greenwald, R. A., Sofko, G., Villain, J.-P., Lepping, R. P., and Hairston, M. R.: SuperDARN studies of the ionospheric convection response to a northward turning of the interplanetary magnetic field, Ann. Geophys., 16, 549-565, 1998, http://www.ann-geophys.net/16/549/1998/.

Todd, H., Cowley, S. W. H., Lockwood, M., Willis, D. M., and Luhr, H.: Response time of the high latitude day side ionosphere to sudden changes in the north-south component of the IMF, Planet. Space Sci., 36, 1415-1428, 1988.

Vickrey, J. F. and Kelley, M. C.: The effects of a conducting E layer on classical F region cross-field plasma diffusion, J. Geophys. Res., 87, 4461-4468, 1982.

Weimer, D. R.: Models of high-latitude electric potentials derived with a least error fit of spherical harmonic coefficients, J. Geophys. Res., 100, 19595-19608, 1995.

Østgaard, N., Mende, S. B., Frey, H. U., Frank, L. A., and Sigwarth, J. B.: Observations of non-conjugate theta aurora, Geophys. Res. Lett., 32, L2125, doi:10.1029/2003/GL017914, 2003. 